\title{
CALCITONIN GENE-RELATED PEPTIDE: POSSIBLY NEUROTRANSMITTER CONTRIBUTES TO PENILE ERECTION IN MONKEYS
}

\author{
CHRISTIAN GEORG STIEF, M.D. \\ FRANCOIS BENARD, M.D. \\ RUUD BOSCH, M.D. \\ SHERIF ABOSEIF, M.D.
}

\author{
ULRICH WETTERAUER, M.D. \\ TOM F. LUE, M.D. \\ EMIL A. TANAGHO, M.D.
}

From the Department of Urology, University of California, San Francisco, California

\begin{abstract}
The distribution of calcitonin gene-related peptide (CGRP) immunoreactivity in the cavernous tissue and the erectile response to intracavernous injection of CGRP was investigated in 7 monkeys. Intracavernous CGRP increased cavernous arterial flow and induced cavernous smooth muscle relaxation and venous outflow occlusion. Intracavernous injection of CGRP antibody did not significantly change the erectile response to cavernous nerve stimulation. Histologic staining for CGRP immunoreactivity showed nerve fiber-like staining within the cavernous arterial wall and the cavernous smooth muscles. These data suggest that CGRP may contribute to penile erection in monkeys.
\end{abstract}

In 1863 Eckhard $^{1}$ reported that canine penile erection could be induced by stimulation of pelvic parasympathetic nerves. Although acetylcholine is the presumed postganglionic parasympathetic neurotransmitter, ${ }^{2}$ Anrep and $\mathrm{Cy}$ bulsky ${ }^{3}$ showed about a hundred years ago, that penile erection is atropine-resistant. The latter findings were confirmed in many other studies. ${ }^{4-12}$

More recently, we reported that nerve-stimulation-induced erections in monkeys and dogs could be reduced, but not abolished after muscarinic blockade by intracavernous injection of atropine. ${ }^{13,14}$ These data showed that acetylcholine was only partly responsible for penile erection, suggesting the presence of additional postganglionic parasympathetic neurotransmitters. A candidate for this noncholinergic parasympathetic neurotransmitter is calcitonin gene-related peptide (CGRP), ${ }^{15}$ a potent vasodilator $^{16-18}$ and smooth muscle relaxant. ${ }^{18-22}$ High concentrations of immunoreactive CGRP are found in penile tissue of the rat. ${ }^{23}$ In this in vivo study, we examined functionally and histo- logically the contribution of CGRP to penile erection in monkeys.

\section{Material and Methods}

Seven pigtail monkeys, weighing 4.3 to 8.3 $\mathrm{kg}$, were used. After adequate anesthesia with ketamine $(30 \mathrm{mg} / \mathrm{kg}$ body weight i.m.), the monkeys were placed in the supine position. Under sterile conditions, a 21-gauge scalp-vein needle was placed bilaterally in the distal cavernous body. One needle was connected to a Statham transducer (model P23 BC) for intracavernous pressure recording (Grass Polygraph; model 7); the other was used for intracavernous injection or perfusion. Penile tumescence was visually monitored by two investigators and recorded; classification of tumescence was done according to the following parameters: $\mathrm{E}-0=$ no tumescence; E-1 = slight tumescence; E-2 $=$ partial tumescence; $\mathrm{E}-3=$ full tumescence. The flow through the cavernous arteries was measured in 4 monkeys by duplex ultrasound. ${ }^{24}$ Pulse and blood pressure were monitored closely with the aid of a Doppler probe (Parks 


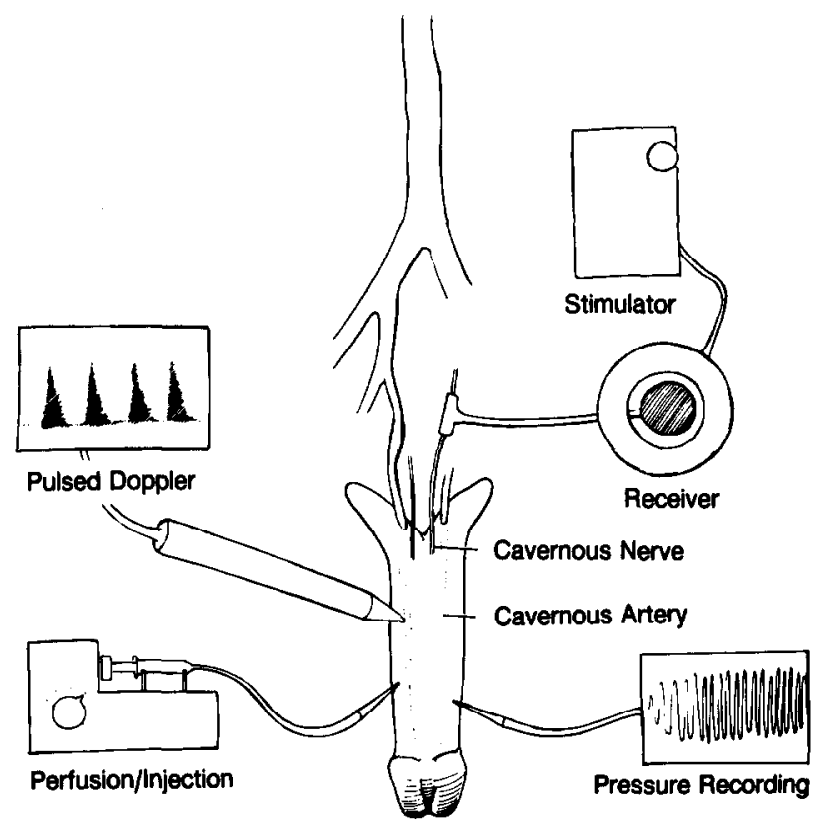

Figure 1. Schematic shows experimental set-up.

Medical Electronics) on the radial artery and a pediatric blood pressure cuff.

\section{Intracavernous injection of CGRP}

In a pilot study, we injected 50,500 , and $2,500 \mathrm{ng}$ CGRP intracavernously in 2 monkeys. A total of $50 \mathrm{ng}$ CGRP induced only a slight, short-lasting tumescence. Because the intracavernous injection of 2,500 ng CGRP lowered the systemic blood pressure by about $35 \mathrm{~cm}$ $\mathrm{H}_{2} \mathrm{O}$, and the erectile response was similar (only longer lasting) to the response to $500 \mathrm{ng}$, a dose of $500 \mathrm{ng}$ CGRP was chosen for the following study.

All monkeys received a dose of $500 \mathrm{ng}$ CGRP (Sigma Chemical Co., St. Louis, MO) by intracavernous injection. To verify reproducibility, the injection was repeated on a second day.

\section{Effect of CGRP on cavernous outflow}

In all monkeys, the penis was perfused with saline $\left(37^{\circ} \mathrm{C}\right)$ at a rate of $26.7 \mathrm{~mL} / \mathrm{min}$ before and one minute after $500 \mathrm{ng}$ CGRP intracavernously. When the perfusion had continued for sixty seconds or the intracavernous pressure surpassed $300 \mathrm{~cm} \mathrm{H}_{2} \mathrm{O}$ (off scale), it was stopped. After a five-minute period, the penis was reperfused. The perfusion series was stopped when two subsequent perfusions evoked responses equal to that prior to the intracavernous injection of CGRP.

\section{Erections induced by neurostimulation before} and after CGRP-antibody

In 6 monkeys, cuff electrodes were placed around the cavernous nerve as previously described. ${ }^{25}$ After three erections had been in- duced by neurostimulation $(20 \mathrm{~Hz}, 6$ to $8 \mathrm{~V}$, stimulation time $=1$ minute), $500 \mathrm{ng}$ CGRPantibody (Penninsula Lab.) were injected intracavernously and neurostimulation was repeated after one minute and then three times with an eight-minute interval between each stimulation (Fig. 1).

\section{Histologic staining for CGRP-immunoreactivity}

In 2 monkeys, the aorta was clamped and the cavernous bodies were perfused with $500 \mathrm{~mL}$ saline, followed by $500 \mathrm{~mL}$ phosphate buffer $(0.1 \mathrm{M})$ and fixed with $500 \mathrm{~mL}$ phosphate buffered $4 \%$ paraformaldehyde. All perfusion solutions were at $4^{\circ} \mathrm{C}$. The cavernous bodies were removed and sections of approximately $0.5 \mathrm{~cm}$ long were placed in the fixation solution for thirty minutes at $4^{\circ} \mathrm{C}$. After overnight rinsing in $30 \%$ sucrose, the tissues were embedded (Tissue Tek, Miles Scientific, Naperville, IL) and frozen.

An indirect immunofluorescence technique was used to locate CGRP-immunoreactive fibers. ${ }^{26}$ Cryostat sections were cut $(16 \mu \mathrm{m})$ and placed on lycine-coated slides. The sections were rehydrated with buffer $(0.05 \mathrm{M}$ PBS + $0.3 \%$ Triton-X 100, pH 7.4) for five minutes, then preincubated at room temperature for thirty minutes with $5 \%$ goat serum in buffer. After draining but not rinsing, the sections were incubated in a humidified chamber for fortyeight to seventy-two hours at $4^{\circ} \mathrm{C}$ with an antibody to CGRP raised in rabbits (Penninsula Lab., San Carlos, CA), dilution 1:100. After three ten-minute washes in buffer, the slides were incubated for thirty minutes at $37^{\circ} \mathrm{C}$ in goat anti-rabbit IgG conjugated to fluoresceinisothiocyanate (FITC) (Cooper Biomedical, Malvern, PA) diluted 1:50. The sections were then washed, mounted with glycerol:PBS $(9: 1)$ containing 1.5\% 1,4-Diazabicyclo [2.2.2] octane, pH 8.6 (DABCO, Sigma Chemical), and viewed with an Olympus microscope equipped for viewing FITC fluorescence. As method control, tissues were prepared as mentioned, but without adding CGRP-antibody. Statistical analysis was done using the Student $t$-test.

\section{Results}

\section{Intracavernous injection of CGRP}

The first change after the intracavernous injection of $500 \mathrm{ng}$ CGRP was an increase in arterial flow. This was followed by penile tumescence, and then after about one minute, by an 


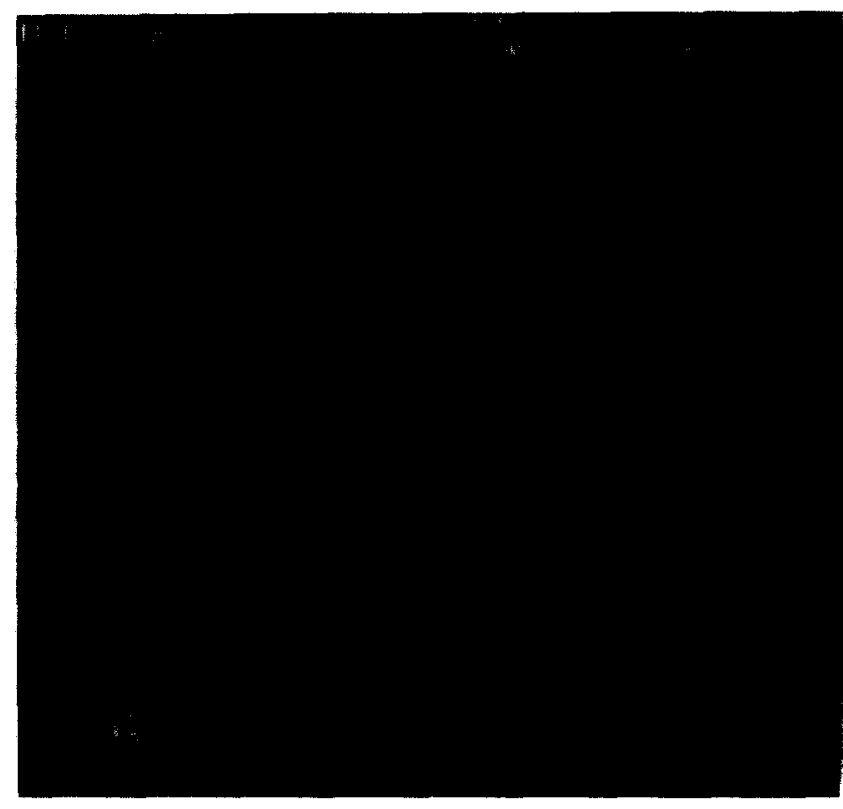

Figure 2. (A) In flaccid state, simian cavernous artery could not be detected by pulsed Doppler. $(B)$ and (C) After intracavernous injection of CGRP, high-flow velocity within cavernous artery was measured.

increase in intracavernous pressure. Prior to intracavernous injection of CGRP, we could not measure flow velocity of the cavernous artery by duplex ultrasound. After intracavernous injection of CGRP, there was a gradual increase in flow velocity. The flow velocity of the cavernous artery peaked at four minutes (mean) after the injection of CGRP. The maximum flow velocity diminished three to four minutes later. We could not detect an arterial flow thirty-two to sixty-nine minutes (mean $49 \mathrm{~min}$ ) after the intracavernous injection of CGRP (Fig. 2).

Penile tumescence increase was observed about thirty to sixty seconds after the CGRP injections. Maximal tumescence and elongation (E-3) was seen at the time of maximal arterial inflow (mean 4 min after injection) until up to fifteen minutes after the injection. Tumescence then gradually decreased; after a mean of thirty-two minutes, no difference between the tumescence before and after the injection of CGRP could be detected. Intracavernous pressure before CGRP-injection was twenty-four to forty-five $\mathrm{cm} \mathrm{H}_{2} \mathrm{O}$ (mean 34). Within ninety to one hundred twenty seconds after the injection, the intracavernous pressure rose to a mean maximum pressure of 62 to $94 \mathrm{~cm} \mathrm{H}_{2} \mathrm{O}$ (mean 78). Two to four minutes later, the intracavernous pressure fell within less than sixty seconds to a

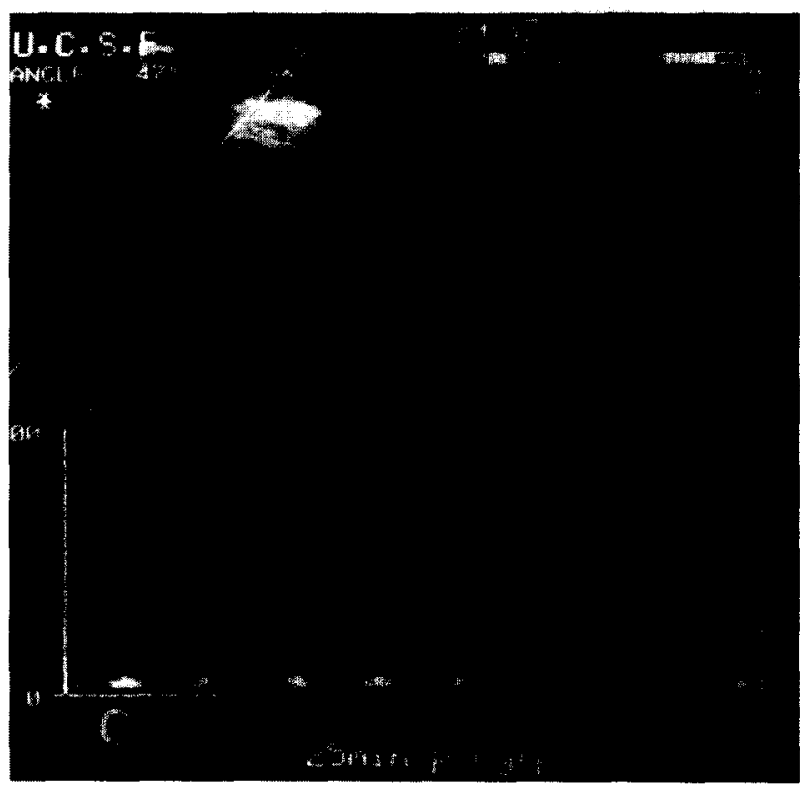

mean pressure level of 40 to $54 \mathrm{~cm} \mathrm{H}_{2} \mathrm{O}$ (mean 47). This pressure gradually declined until baseline pressure was reached after a mean of thirty-six minutes.

\section{Effect of CGRP on cavernous outflow}

In the monkeys, saline perfusion at $26.7 \mathrm{~mL} /$ min induced an intracavernous pressure of mean $143 \mathrm{~cm} \mathrm{H}_{2} \mathrm{O}$ and slight penile tumescence and elongation $(\mathrm{E}-1)$. The response to saline perfusion one minute after the CGRP injection was equal to that before the injection, suggesting that the cavernous smooth muscles are still in the contracted state. After five minutes, saline perfusion showed full venous occlusion 
Figure 3. (A) Control perfusion of cavernous body with saline alone. (B) Long-lasting venous occlusive effect shown after intracavernous injection of CGRP (arrow at minute 0).

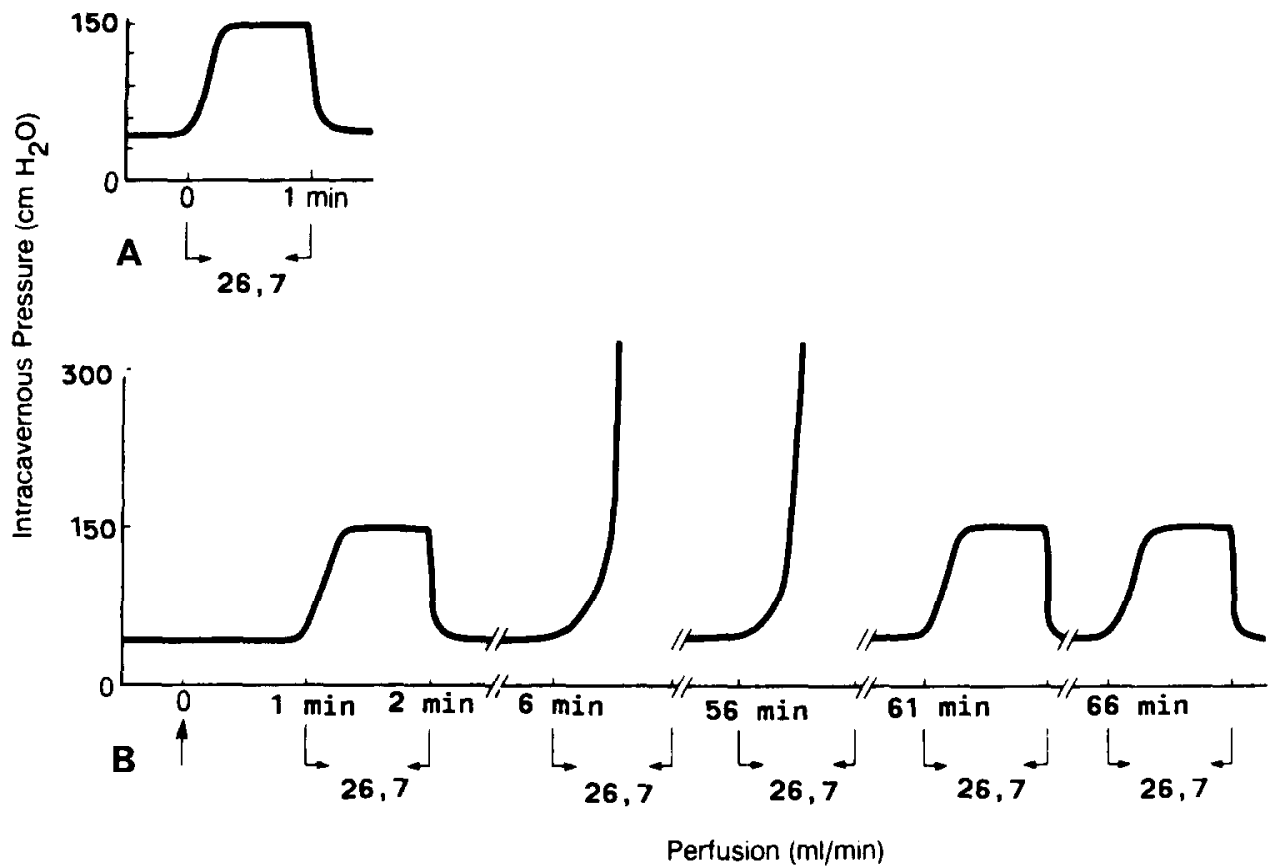

(and consequently cavernous smooth muscle relaxation) with full erection in 6 of 7 monkeys; this lasted forty-five to eighty minutes (mean 55). In one monkey, full venous occlusion could not be achieved by a perfusion rate of $26.7 \mathrm{~mL} /$ min (Fig. 3).

Erections induced by neurostimulation before and after CGRP-antibody

In all monkeys, the erectile response to neurostimulation was not significantly changed after the intracavernous injection of $500 \mathrm{ng}$ CGRP antibody.

\section{Histologic staining for \\ CGRP-immunoreactivity}

In the control slides, unspecific staining was found within the endothelium of the arteries. In the slides stained for CGRP immunoreactivity (CGRP-1), nerve fiber-like CGRP-1 was found within the walls of the cavernous arteries and within the cavernous smooth muscles. Dense varicosity-like staining was also found within the cavernous smooth muscles (Fig. 4).

\section{Comment}

Intracavernous injection of CGRP induced an erectile response. This response was due to an increase in arterial flow, relaxation of the cavernous smooth muscles, and occlusion of the venous outflow. The changes in the arterial flow were shown by Duplex sonography of the

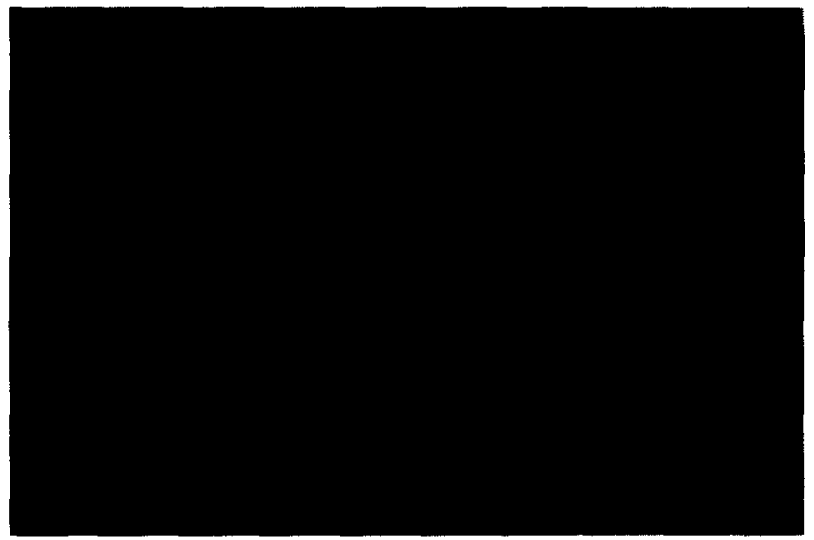

Figure 4. Dense varicosity-like staining was found within simian cavernous smooth muscles (original magnification $\times 400$ ).

cavernous arteries. Relaxation of the cavernous smooth muscles by CGRP was demonstrated by penile tumescence and by the perfusion studies: saline perfusion alone at a rate of $26.7 \mathrm{~mL} / \mathrm{min}$ induced a mean intracavernous pressure of 143 $\mathrm{cm} \mathrm{H}_{2} \mathrm{O}$, corresponding to the intracavernous pressure of a full erection induced by neurostimulation. ${ }^{25}$ However, saline perfusion alone induced only a slight penile tumescence and elongation. This is probably due to contracted cavernous smooth muscles with subsequent incomplete expansion of cavernous spaces and therefore incomplete penile tumescence. In contrast, the same perfusion rate induced full erection after intracavernous injection of 
CGRP. Probably, this reflects complete cavernous smooth muscle relaxation with subsequent cavernous outflow restriction. ${ }^{27}$ The presence of CGRP immunoreactive fibers in cavernous arteries and cavernous smooth muscles provide an anatomic base for these in vivo findings.

Our histologic findings of CGRP-1 in cavernous arteries and smooth muscles are supported by the study of Wimalawansa, Emson, and MacIntyre ${ }^{23}$ showing a high concentration of CGRP binding sites in rat penile tissue extracts. Arterial dilatation to CGRP in man and different animal species was found in vivo ${ }^{16,17}$ and in vitro. ${ }^{18}$ Furthermore, other in vitro studies showed that CGRP is a potent relaxant of the smooth muscle of the intestine ${ }^{19}$ and the vas deferens. ${ }^{20-22}$

Intracavernous injection of CGRP antibody did not significantly change the erectile response to neurostimulation. In contrast to VIP antibody that also has a VIP antagonistic effect, ${ }^{28}$ CGRP antibody seems to have no CGRP antagonistic effect.

Our findings suggest a possible role for CGRP as neurotransmitter/cotransmitter for penile erection. Further studies are needed to investigate the possibility of therapeutic applications of CGRP in erectile dysfunction. Intracavernous application of CGRP may be tried, given the appropriate indication and careful patient selection.

\section{Department of Urology MHH, Medical School D-3000, Hannover 61 Germany} (DR. STIEF)

\section{References}

1. Eckhard C: Untersuchungen über die Erektion des Hundes, Beitr Anat Physiol 3: 123 (1863).

2. Mayer SE: Neurohumoral transmission and the autonomic nervous system, in Goodman A, and Gilman LS (Eds): The Pharmacological Basis of Therapeutics, New York, Macmillan, vol 7, chap 4, 1985, p 56 .

3. Anrep B, and Cybulsky N: Zur Physiologie der gefässerweiternden und gefässverengenden Nerven, St. Petersburg med Wchnscher 20: 215 (1884).

4. Henderson VE, and Roepke MH: On the mechanism of erection, Am J Physiol 106: 441 (1933).

5. Dorr LD, and Brody MJ: Hemodynamic mechanisms of erection in the canine penis, Am J Physiol 213: 1526 (1967).

6. Siroky MB, and Krane RJ: Neurophysiology of erection, in Krane RJ, Siroky MB, and Goldstein I (Eds): Male Sexual Dysfunction, Boston, Little Brown and Co, 1983.
7. Lue TJ, et al: Hemodynamics of erection in the monkey, J Urol 130: 1237 (1983).

8. Carati CJ, Creed KE, and Keogh EJ: Autonomic control of penile erection in the dog, J Physiol 384: 525 (1987).

9. Wagner G, and Brindley GS: The effect of atropine and alpha and beta blockers on human penile erection: a controlled pilot study, in Zorgniotti AW, and Rossi G (Eds): Vasculogenic impotence, Springfield, Charles C Thomas, 1978, p 77.

10. Brindley GS: Pilot experiments on the actions of drugs injected into the human corpus cavernosum penis, $\mathrm{Br} J$ Pharmacol 87: 495 (1986).

11. McConnell J, Benson GS, and Wood J: Autonomic innervation of the mammalian penis: a histochemical and physiological study, J Neural Transm 45: 227 (1979).

12. Benson GS, et al: Neuromorphology and neuropharmacology of the human penis: an in vitro study, J Clin Invest 65: 506 (1980).

13. Stief CG, et al: Acetylcholine as possible neurotransmitter in penile erection, J Urol 141: 1444 (1989).

14. Stief CG, et al: A possible role of acetylcholine for canine penile erection, Urol Int 44: 357 (1989).

15. Amara SG, et al: Alternative RNA processing in calcitonin gene expression generates mRNAs encoding different polypeptide products, Nature 298: 240 (1982).

16. Brain $\mathrm{SD}$, et al: Calcitonin gene-related peptide is a potent vasodilator, Nature 313: 54 (1985).

17. McEwan J, et al: Calcitonin gene-related peptide: a potent dilator of human epicardial coronary arteries, Circulation 74: 1243 (1986).

18. Törnebrandt K, Nobin A, and Owman C: Contractile and dilatatory action of neuropeptides on isolated human mesenteric blood vessels, Peptides 8: 251 (1987).

19. Bartho L, Lembeck F, and Holzer P: Calcitonin gene-related peptide is a potent relaxant of intestinal muscle, Eur J Pharmacol 135: 449 (1987).

20. Goto K, Kimura S, and Saito A: Inhibitory effect of calcitonin gene-related peptide on excitation and contraction of smooth muscles of the rat vas deferens, J Pharmacol Exp Ther 241: 635 (1987)

21. Al-Kazwini B, Craig AK, and Marshall I: Postjunctional inhibition of contractor responses in the mouse vas deferens by rat and human calcitonin gene-related peptides, J Pharmacol 88: 173 (1986).

22. Ohhashi T, and Jacobowitz DM: Effect of calcitonin generclated peptide on the neuroeffector mechanism of sympalhetic nerve terminals in rat vas deferens, Peptides 4: 987 (1985).

23. Wimalawansa SJ, Emson PC, and MacIntyre I: Regional distribution of calcitonin gene-related peptide and its specific binding sites in rats with particular reference to the nervous system, Neuroendocrinology 46: 131 (1987).

24. Lue TF, Hricak H, Marich KW, and Tanagho EA: Vasculogenic impotence evaluated by high-resolution ultrasonography and pulsed Doppler spectrum analysis, Radiology 155: 777 (1987).

25. Lue TF: The mechanism of penile erection in the monkey, Semin Urol 4: 217 (1986).

26. Coons AH, Leduc EH, and Connolly JM: Studies on antibody production. I. A method for the histochemical demonstration of specific antibody and its application to a study of the hyperimmune rabbit, J Exp Biol 102: 49 (1955).

27. Juenemann KP, Luo JA, Lue TF, and Tanagho EA: Further evidence of venous outflow restriction during erection, $\mathrm{Br} \mathrm{J}$ Urol 58: 320 (1986).

28. Juenemann K-P, et al: The role of vasoactive intestinal polypeptide as a neurotransmitter in canine penile erection: a combined in vivo and immunohistochemical study, J Urol 138 . 871 (1987). 